\title{
WITTGENSTEIN, GEERTZ Y LA COMPRENSIÓN DE METÁFORAS
}

\author{
EDUARDO FERMANDOIS \\ Instituto de Filosofía \\ Pontificia Universidad Católica de Chile \\ eferman02@yahoo.de
}

\begin{abstract}
RESUMEN: El objetivo del artículo es describir rasgos estructurales de la comprensión de metáforas mediante una comparación con la comprensión de otras culturas, tal como ésta ha sido comentada por Wittgenstein y Geertz. El fenómeno de estudio es la comprensión enfática (no básica) de metáforas fuertes (no de metáforas convencionales y muertas). La comparación entre ambos tipos de comprensión sirve para plantear y dar respuesta a tres preguntas desatendidas en la profusa literatura sobre la metáfora: 1) ¿En qué sentido nos sorprenden las metáforas fuertes? 2) ¿En qué sentido pueden ser profundas? 3) ¿En qué sentido hablamos de la riqueza de este fenómeno lingüístico?
\end{abstract}

PALABRAS CLAVE: traducción, juegos de lenguaje, contexto, descripción densa, red metafórica

SUMMARY: This paper sets out to describe the structural features of metaphor comprehension through a comparison with the process of understanding other cultures construed along the lines proposed by Wittgenstein and Geertz. The phenomenon under analysis is the emphatic (not basic) understanding of strong (not conventional or dead) metaphors. The comparison between understanding metaphors and cultures serves to raise and answer three questions that have been neglected in the vast literature on metaphors: 1) In which sense do strong metaphors surprise us? 2) In which sense can a metaphor be profound? 3) In which sense do we speak of the richness of this linguistic phenomenon?

KEY WORDS: translation, language games, context, thick description, metaphorical network

\section{Comparaciones}

Más de un capítulo en la investigación contemporánea del lenguaje ha puesto de manifiesto, casi sin proponérselo, que la comparación entre fenómenos lingüísticos constituye un fecundo ejercicio teórico. Quine y Davidson imaginaron en detalle a una persona que ha de ingeniárselas para traducir un lenguaje radicalmente diferente al suyo, elaborando a partir de tal examen ideas memorables sobre el significado lingüístico en general. De carácter general fueron también las enseñanzas que Wittgenstein obtuvo sobre la comprensión lingüística, cuando la comparó con el proceso de transformar en sonidos lo escrito (de leer, en ese sentido). Más recientemente, Frankfurt ha delatado 
la charlatanería (bullshit) mostrando sus diferencias con la mentira, mientras que Williams revela contrastes entre esta última y la falta de precisión (accuracy). ${ }^{l}$ Acercándonos a nuestro tema, cabe recordar la analogía entre metáforas y chistes, propuesta, con distintos fines, por Davidson y por Cohen, o el interés de Hesse por explicar una metaforicidad fundamental de todo lenguaje natural a partir de la idea wittgensteiniana de los parecidos de familia. ${ }^{2}$ Sin embargo, son otros dos textos los que, por consistir de principio a fin en ejercicios de comparación, me han inspirado más directamente: "Metaphor and the Main Problem of Hermeneutics" de Paul Ricœur y "Metaphor and Aspect Seeing" de Marcus Hester. ${ }^{3}$ El primero trabaja con la hipótesis de que una metáfora es un breve poema, una obra en miniature; el segundo compara la visión de aspectos (la estudiada por Wittgenstein en la figura del pato-conejo) y aquel descubrimiento de aspectos que, según Hester, opera también en la comprensión de metáforas. Las consideraciones que siguen se enmarcan entonces en una pequeña tradición. En ella confluyen involuntariamente textos que, por muy distinto que procedan en otros respectos, buscan sin excepción esclarecer un fenómeno mostrando sus semejanzas y diferencias con relación a otro. ${ }^{4}$

El propósito del presente ensayo comparativo es detectar en qué medida la comprensión del lenguaje y las costumbres de una cultura muy diferente de la nuestra - hablaré también, para simplificar, de "comprensión intercultural" - se presta para iluminar aspectos estructurales de nuestro modo de comprender metáforas (o, más precisamente, cierto tipo de metáforas). Se trata, como en los casos anteriores, de una caracterización indirecta; de aprender, esta vez sobre la interpretación de metáforas, estableciendo paralelos, y alguna diferencia, con respecto a otro fenómeno interpretativo. ${ }^{5} \mathrm{Y}$ aunque no sea su objetivo central, el cotejo servirá de paso para explicitar rasgos

${ }^{1}$ Cfr. Frankfurt 2006 y Williams 2006. Las alusiones anteriores se refieren, desde luego, a Quine 1968, Davidson 1995 y Wittgenstein 1988. El caso de la lectura es tratado entre los parágrafos 156 y 171 de este último texto.

${ }^{2}$ Cfr. Davidson 1999, Cohen 1979 y Hesse 1993.

${ }^{3}$ Cfr. Ricœur 1974 y Hester 1966.

${ }^{4}$ Hago un par de reflexiones sobre la comparación como instrumento teórico en "Metáforas en filosofía" (que se publicará próximamente en el volumen Filosofía de la filosofía, editado por Oscar Nudler, de la Enciclopedia Iberoamericana de Filosofía).

${ }^{5}$ Ensayo una descripción directa de la interpretación metafórica en "Imagen, aspecto y emoción. Apuntes para una fenomenología de la metáfora", texto que aparecerá este año en Ideas y Valores. Revista Colombiana de Filosofía y que complementa al presente trabajo. 
no tan evidentes de la comprensión intercultural. Suele ocurrir: el analogado también sale favorecido.

Es ésta una temática sobre la cual no existe bibliografía específica, por lo que el trabajo adquiere inevitablemente un carácter exploratorio. Con todo, las reflexiones de dos autores servirán como apoyo y control de lo que en otro caso correría el riesgo de convertirse en especulación sin engarce. Se trata de indicaciones hechas por Wittgenstein, sobre todo en sus Comentarios sobre La rama dorada, y de otras expuestas por el antropólogo Clifford Geertz, principalmente en sus dos artículos teóricos más importantes: "Descripción densa: hacia una teoría interpretativa de la cultura" y "Desde el punto de vista del nativo': sobre la naturaleza del conocimiento antropológico". Al escribir que "la cultura es pública porque la significación lo es" (2000a, p. 26), Geertz deja en evidencia la profunda influencia que el último Wittgenstein ejerce en su pensamiento ( $c f r$. también Geertz 2001, p. xii). Pero espero poder mostrar que las coincidencias entre ambos no sólo son de fondo. En suma: la siguiente descripción de la comprensión de metáforas a la luz de la comprensión de culturas se orienta por reflexiones que ambos autores han hecho sobre esta última, y quiere servir de confirmación a ellas. De ahí el título del trabajo.

\section{Los sentidos de la sorpresa}

La comprensión intercultural y la comprensión de metáforas tienen en común, por de pronto, ser un desafío frente a lo extraño. Escuchamos enunciados proferidos en una lengua que no tiene el menor parecido con la nuestra, sin poder recurrir a diccionarios bilingües (que no se han escrito) o semejanzas fonéticas (que no existen); somos testigos de prácticas que nos desconciertan, nos escandalizan o ambas cosas: rituales de magia, sacrificios de animales, etc. Todo ello se aplica análogamente a los enunciados metafóricos que aquí nos interesan. Constituye, en efecto, uno de los rasgos distintivos de las metáforas fuertes su capacidad de sorprendernos. ${ }^{6}$ Tomemos el enunciado "Un poema es un pavo real". Hemos oído decir que los poemas constan de versos, que presentan rimas y métricas de diversos tipos, que son bellos, incomprensibles, etc. Pero que sean pavos

\footnotetext{
${ }^{6}$ Tomo la noción de "metáfora fuerte" (strong metaphor) de Black 1993, p. 26. Iré explicando paulatinamente su significado, para resumirlo al final de la tercera sección. Siempre que hable simplemente de "metáforas", me estaré refiriendo a las de este tipo.
} 
reales — esto constituye algo inaudito-. No sólo no hemos oído antes algo semejante (salvo que conozcamos la obra del poeta Wallace Stevens); se trata también de una emisión inaudita, en el sentido de "insólita" y hasta "escandalosa". La clasificación ornitológica de un texto escrito atenta contra toda expectativa lingüística. Las metáforas fuertes representan algo extraño y turbador; nos impresionan como un ritual desconocido.

Desde luego, apuntar a este carácter sorpresivo del fenómeno metafórico no resulta sorpresivo. Pero la comprensión intercultural nos permite dar con el alcance preciso que tiene hablar de una sorpresa originada por una metáfora fuerte. Los seres humanos nos sorprendemos en la vida cotidiana en diversas acepciones de la palabra: una noticia puede tomarnos desprevenidos, como cuando de súbito nos enteramos de un resultado futbolístico insospechado; pero un hecho nos puede sorprender también una y otra vez, como cuando nos asombra la cantidad de tiempo que nos lleva escribir una página, o la dificultad de un amigo para superar tal o cual tara, o la perturbación que una vieja melodía no nos deja de causar. Mientras que el primer sentido de "sorpresa" dice relación con la sorpresa de la primera vez, el segundo sentido tiene que ver con algo que nos impresiona. Pues bien, cuando Wittgenstein describe el efecto de ritos ancestrales o costumbres desconocidas, la palabra de la que más echa mano es precisamente "impresión" (Eindruck). ${ }^{7}$ Frente a tales ritos y costumbres nos sentimos profundamente impresionados, y en este sentido, el segundo de los que acabamos de distinguir, ellos nos sorprenden.

Veamos qué sucede con la metáfora. Refiriéndome a la irrupción de "pavo real" en el contexto lírico, dije que el enunciado nos sorprendía, pues no lo habíamos oído antes e iba contra nuestros hábitos lingüísticos; era el primer sentido de "sorpresa", el de la primera vez. Pero bajo nuestra hipótesis comparativa podemos reparar ahora que, también en la metáfora, el sentido crucial es en realidad el segundo. Nótese que, incluso habiendo encontrado un par de interpretaciones a "El poema es un pavo real", este enunciado nos continúa sorprendiendo, esto es, nos impresiona. Más aún, en nuestra experiencia con metáforas fuertes, éste es el sentido crucial, por ser el más intenso y duradero. El punto queda más claro si tomamos metáforas que hemos escuchado ya muchas veces, como "El Señor es mi Pastor" o "El mundo es un teatro" (aunque obviamente nos han sorprendido

7 "En comparación con la impresión que nos produce lo descrito, la explicación es demasiado insegura" (Wittgenstein 1997, p. 11). He contado al menos otras ocho apariciones de esta palabra en usos similares.

Crítica, vol. 40, no. 118 (abril 2008) 
también alguna vez en el primer sentido). Nuestro trato con estos enunciados demuestra que lo sorpresivo del fenómeno metafórico no corresponde, como pareció en el párrafo anterior, a la sorpresa puntual que conlleva toda primera vez. Aquí, lo sorpresivo no es simplemente lo inusitado. Podemos haber leído miles de veces el registro bíblico del Buen Pastor, o haber observado no en una, sino en muchas ocasiones, el mismo rito de iniciación sexual — por alguna razón a indagar, ambos encuentros nos vuelven a impresionar-. El asunto no tiene que ver con frecuencia o asiduidad; como iremos viendo poco a poco, tiene que ver, más bien, con profundidad y densidad.

El encuentro con culturas lejanas puede ser además el encuentro con lo enigmático, y esto nos permite continuar precisando el sentido del carácter sorpresivo de las metáforas fuertes. En efecto, algunas de ellas se presentan como enigmas, otras no. Algunas nos sorprenden como nos puede sorprender un acertijo, y como una fiesta de sorpresa, paradójicamente, jamás logrará sorprendernos. Pues cuando de pronto se encienden las luces y el festejado ve a los invitados reunidos en su honor, junto con sorprenderse, lo entiende absolutamente todo: sabe de inmediato el porqué de todo lo anterior, lo que ahora corresponde hacer, lo que vendrá a continuación. En la fiesta de sorpresa, sorprenderse es compatible, y simultáneo, con dejar de estarlo. No ocurre así, en cambio, ante el enigma, la adivinanza o el misterio, casos en que sorprenderse significa no saber qué hacer ni qué decir, hallarse perplejo. Algunas metáforas se parecen a las adivinanzas, esto ya lo percibió Aristóteles. ${ }^{8}$ En el caso del poema cual pavo real debemos comenzar a buscar conexiones que por de pronto no se ven por ningún lado. Sin embargo, imágenes incluso tan impresionantes como "El Señor es mi Pastor" no son enigmáticas: damos espontáneamente con alguna interpretación, como, por ejemplo, que Jesús conduce y protege. Ambas metáforas son fuertes porque ambas nos sorprenden, esto es, nos impresionan; pero sólo una de ellas es además un enigma en el sentido en que lo son también, aunque no siempre, ritos o prácticas de otras culturas. En lo que sigue me referiré principalmente a la clase más general de metáforas que — por

8 "Las buenas adivinanzas nos proporcionan metáforas satisfactorias: porque las metáforas implican acertijos, y por tanto un buen acertijo puede suministrar una buena metáfora" (Aristóteles, Retórica 1405a, citado en Rivano 1986, p. 28, quien analiza ejemplos pertinentes). Ahora bien, creo que la metáfora-acertijo, aquella que se comprende de una vez, representa un caso especial y aislado. Más representativa es la metáfora-enigma ("El poema es un pavo real") y más aún la metáfora que nos impresiona en general. 
alguna razón a indagar- nos impresionan, y respecto de la cual las enigmáticas conforman sólo una subclase.

Hablar de "sorpresa" puede tener entonces — en la teoría de la metáfora, como en la vida cotidiana - significados bien diversos. Una copiosa literatura consigna el efecto sorpresivo de metáforas fuertes, pero precisar el sentido de aquél ha sido siempre una inconfesada tarea pendiente. En Rorty se observa un privilegio del primer sentido de la sorpresa, el de la primera vez. Lo sorpresivo consiste, según él, en la aparición súbita de usos lingüísticos impredecibles, por lo que la pregunta "¿cómo operan las metáforas?" le parece tan innecesaria como ésta: "¿cuál es la naturaleza de lo inesperado?" (Rorty 1996, p. 229). Pero Rorty no justifica su unilateral énfasis en la sorpresa puntual - en verdad, ni siquiera se muestra muy consciente al respecto- - La atención a nuestra experiencia real con metáforas fuertes revela en cambio que el privilegio lo posee la impresión que ellas nos causan. Esta afirmación cuenta con un apoyo adicional. Que la metáfora nos sorprenda como nos sorprende lo inusitado haría pensar que también su comprensión es de carácter puntual, en coincidencia con aquel momento en que, de una vez, salimos de la sorpresa. Sin embargo, las metáforas fuertes no se entienden de una vez; como veremos, la comprensión metafórica y la intercultural son procesos graduales y paulatinos. Aquella sorpresa en virtud de la cual queremos comprender no parece ser entonces la sorpresa del momento.

\section{Comprensión enfática frente a traducción}

Detengámonos ahora en el modo de acceder a otro lenguaje (en aras de la brevedad, hablaré de "otro lenguaje" para referirme al lenguaje de una cultura lejana a la propia), para constatar, ante todo, que se trata de modos diversos. Existe, en primer lugar, la traducción simple o literal que traslada directamente contenidos de un lenguaje a otro sin pérdida semántica alguna (o de importancia). Existe, segundo, la traducción compuesta, como cuando debido a una división lingüística más precisa de un segmento de la naturaleza, los hablantes de un dialecto esquimal deben traducir nuestro aserto de que hay nieve, diciendo que hay aput (nieve sobre el suelo) o gana (nieve mientras cae del cielo) o qimuqsuq (nieve arrastrada por el viento). ${ }^{9}$ Otras diferen-

\footnotetext{
${ }^{9}$ Las "o" de la traducción poseen obviamente un sentido excluyente. No menos obvio debiera ser que el recurso a este ejemplo no implica un compromiso con la llamada "hipótesis Sapir/Whorf" o con otras posiciones en la ya larga discusión sobre las palabras de los esquimales para la nieve.
} 
cias pueden llevar a que, tercero, ciertas traducciones - las podemos apellidar de "atrevidas" - necesariamente transformen, en mayor o menor grado, el sentido de ciertas expresiones del original (recuérdense aquí las "notas a la traducción” que consignan las vicisitudes semánticas que implicó la hazaña). Tales diferencias son también, cuarto, la causa de que a veces sólo podamos traducir alterando nuestro propio lenguaje, creando, por ejemplo, nuevas expresiones: si nos encargaran llevar al castellano "qimuqsuq", podríamos introducir un término inédito en nuestro léxico, y produciríamos así su ampliación y, por ende, su modificación. (Dentro de este cuarto grupo hay un subgrupo peculiar: dado que el verbo alemán "sich anmelden" no significa exactamente "inscribirse", hispanoparlantes que residen en países de lengua germana suelen hablar de "anmeldearse".) Quinto, a veces se requieren interpretaciones o explicaciones del largo de un libro y que ya no cabe llamar, en un sentido aún reconocible del término, traducciones. Así, "kabary" designa, en la lengua malagasi, una suerte de discurso formal empleado en ciertos contextos ceremoniales en los que el jefe de la comunidad procede a... En fin, seguramente más de alguien escribe ahora mismo una tesis doctoral sobre la areté griega o el Gemüt alemán. Y, sexto, no queda claro que alguno de estos tipos de traducción e interpretación constituya el acceso primario a otros lenguajes, pues a menudo traducimos o interpretamos al nuestro (o ponemos en circulación el original sin traducir), sólo una vez que hemos aprendido la voz extranjera directamente.

Queda en evidencia, como enseñanza negativa, que la traducción simple o literal, con su lógica del uno a uno, representa apenas un posible modo de comprender otro lenguaje. Incluso si agregamos las otras dos variantes de traducción (la compuesta y la que atrevidamente vierte con imprecisión el sentido original), veremos que traducir es sólo una alternativa entre otras. La ecuación entre comprensión y traducción queda ya mal parada si se piensa en el aprendizaje de la lengua materna. Pero tales procesos de aprendizaje se repiten en la adultez, y no sólo cuando nos hacemos de nuevos conceptos mediante palabras de nuestra lengua que desconocíamos, sino también al aprender una lengua extranjera capaz de articular conceptos para los que la nuestra no dispone de palabras. ${ }^{10}$

Ahora bien, la enseñanza negativa nos conduce a un primer rasgo, negativo también, de la interpretación metafórica: tampoco ésta

${ }^{10}$ Las últimas líneas apuntan al meollo de una crítica a la interpretación radical de Davidson, entendida ésta como modelo de comprensión lingüística en general. $C f r$. Fermandois 2003, especialmente las pp. 78-82. 
posee la dinámica de una traducción. (Su estructura, muy distinta, será revisada más adelante.) Decimos a veces traducir el enunciado metafórico a lenguaje literal; pero tal modo de hablar sólo es parcialmente correcto. Es correcto si se trata de una metáfora convencional o una definitivamente muerta: como cuando se dice "La Crítica de la razón pura es una mina de oro", para afirmar que es un libro del cual se puede aprender mucho, o cuando se habla de "atacar" una tesis para referirse, en acostumbrada clave bélica, a su crítica. En tales casos vemos operando, efectivamente, la lógica del uno a uno. Pero si tomamos ahora la metáfora "Un poema es un estrechón de manos" de Celan, seremos incapaces de señalar el enunciado literal equivalente. Tampoco podremos hacer valer aquí lo que llamábamos "traducción compuesta", porque frente a una metáfora fuerte como la de Celan tampoco cabe buscar un parafraseo compuesto, análogo a "aput o gana o qimuqsuq". El sentido de esta traducción compuesta es el de "aput o... - - y punto—"; y existe un problema con el "y punto". A lo que voy: la interpretación de una metáfora fuerte es esencialmente abierta o indeterminada. No es posible estipular dónde acaba la interpretación de metáforas que dan mucho que pensar, sin que nunca quede claro cuánto. El deseo de la interpretación o la interpretación completa es un deseo reñido con la idea misma de una metáfora fuerte (lo que, claro, no implica negar que haya interpretaciones mejores y peores). Cabe expresar el asunto en términos ilocucionarios: decir que la Crítica de la razón pura es una mina de oro constituye una afirmación; decir, en cambio, que un poema es un estrechón de manos, es, más bien, cursar una invitación. Un teólogo leído y avezado siempre podrá sacarle un matiz inesperado al aforismo evangélico "El Señor es mi Pastor". Idénticos son el caso de un escritor inspirado en "La vida es un carnaval" y el de un filósofo cavilando sobre "Las palabras son herramientas". Lo que ninguno de los tres hace es traducir; ni simple ni compuestamente.

Se podría alegar lo siguiente: si alguien interpreta la metáfora de Celan diciendo que cuando leemos un poema descubrimos a un ser humano intentando crear un lazo de cercanía con nosotros, nadie vacilaría en afirmar que la imagen, de alguna manera, ha sido comprendida. ¿Por qué negarse entonces a que la comprensión metafórica presenta la misma estructura uno a uno, o al menos nada significativamente diferente, que la de la traducción literal? Esta objeción no es motivo para desistir de nuestra tesis negativa, pero nos obliga a precisarla. Hemos de distinguir entre dos conceptos de comprensión metafórica: un concepto débil o básico y un concepto fuerte o enfático. Quien ofrece el comentario recién consignado cuenta con cierta 
comprensión, eso es indudable; pero no lo es menos que quien escribe veinte páginas sobre la misma metáfora posee una comprensión mucho más desarrollada. O para continuar con Celan: una cosa es decir que su clásica expresión "leche negra del amanecer" alude a la terrible realidad del Holocausto; otra distinta es escribir un ensayo sobre la no menos terrible imagen poética. En el primer caso, un intérprete se contenta — por falta de interés, idoneidad, tiempo o lo que sea- con un primer parafraseo; éste, es cierto, le permite excluir la posibilidad de que el lenguaje haya sido simplemente mal usado, pero no le permite mucho más. En el segundo, el intérprete ofrece varias interpretaciones y las va ligando entre sí, ocupa "pequeñas metáforas" generadas por la metáfora central, ilumina el origen histórico de ésta, la contrasta con otras imágenes sobre el tema, etc. Pues bien, si esta distinción, que no por ser eminentemente gradual deja de ser una distinción, refleja algo real (como realmente creo), entonces resulta natural emplearla para hacer frente a la objeción. Concedo que se puede ver la comprensión metafórica como traducción: cuando se trata de una comprensión básica; pero insisto en que la comprensión metafórica no presenta la lógica de la traducción cuando es enfática. No se piense, por lo demás, que esta última es monopolio de críticos literarios; la mayoría de nosotros llegaría a muchas interpretaciones de la vida vista como un carnaval, si hiciéramos lo que generalmente no hacemos: dedicar un rato a reflexionar sobre el asunto. Sea como sea, en lo que sigue sólo me interesará el caso de la comprensión enfática.

En la sección anterior dijimos que las metáforas fuertes impresionan; ahora hemos visto que se trata de metáforas abiertas. ${ }^{11}$ Además, hemos identificado la comprensión enfática, de la cual sabemos hasta ahora que funciona de un modo estructuralmente distinto que la traducción. Dicho sea de paso, y por razones similares, tampoco se debe analizar la interpretación de una metáfora a la luz de su traducción a otro idioma. Como hemos visto, a la interpretación le es intrínseca una indeterminación, mientras que la traducción - con todos sus riesgos y controvertibles decisiones - es un asunto terminante. Ambas pueden ser arduas empresas, ambas fascinantes, porque se intima con hechos lingüísticos sin precedentes. Pero la dificultad y el encanto son diferentes en cada caso: el intérprete de la metáfora

\footnotetext{
${ }^{11}$ Esta indeterminación o apertura distingue la metáfora fuerte no sólo de otros tipos de metáforas, sino también del resto de figuras retóricas o literarias. En el caso de ironías simples o convencionales, por ejemplo, vemos operando una regla que lleva de una afirmación dada a su negación. Tampoco es asunto abierto o indeterminado la interpretación de metonimia y sinécdoque, de hipérbole y lítotes.
} 
no conoce el dilema de tener que optar por una entre dos o más posibilidades; a cambio de ello, el traductor de esa misma metáfora puede contemplar su trabajo ya acabado, una vez que ha escogido una variante. La fascinación del traductor debe mucho al vértigo que produce pensar que, tras la complicada elección, ya no habrá vuelta atrás; lo que fascina al intérprete es precisamente que la tarea jamás concluye, que se la puede retomar una y otra vez con nuevos beneficios.

\section{Las importancias del contexto}

Si existe una idea inconfundible en la tardía concepción wittgensteiniana del lenguaje que puede resultar fecunda para una reflexión metodológica de las ciencias sociales en general, y de la antropología en particular, se trata de aquella que el filósofo vienés depositó en la palabra "entretejimiento" (Verwobenheit): el entretejimiento indisoluble entre lenguaje y práctica social, la imbricación entre acciones lingüísticas y no lingüísticas. La idea de tal entretejimiento inspira la noción de juegos de lenguaje y, en un horizonte más amplio, la de formas de vida. Alterando levemente un ejemplo tomado del filósofo noruego Jacob Meløe ( $c f r$. Meløe 1986), quisiera mostrar a continuación la relevancia de todo esto para el tema que nos ocupa.

Un alemán y un indígena mbuti (África central) han entablado amistad y van un buen día a comprar unos botones en Hamburgo. El vendedor señala: "Das macht zwölf Euro" ("Son doce euros"). El alemán paga con un billete de veinte euros y recibe de vuelto ocho monedas. A la salida, el mbuti le pregunta — en el idioma mbuti, que su amigo ha aprendido con germana eficiencia- qué dijo el vendedor. Pero responder a esta pregunta, aparentemente tan sencilla, acaba tornándose una tarea imposible. Es preciso tener en cuenta que en la correspondiente región del África central no se conoce la compra y venta de mercancías mediante dinero. En su aprieto, el alemán recurre al concepto de trueque, que el amigo mbuti sí domina. Pero éste no puede entender, claro, que el vendedor desee trocar un montón de botones nuevos por un papel sucio y ajado. Y, por lo demás, ¿qué diablos querría a cambio de los ocho metales preciosos que entregó al final?... Meløe elabora ingeniosamente otros detalles del ejemplo, pero lo expuesto ya es suficiente para captar el punto central: el mbuti pide una traducción y el alemán no se la puede dar. No hay en el idioma mbuti correlatos para el léxico relacionado con la compra y el dinero, y esto, obviamente, porque no existe en esa 
cultura la correspondiente práctica. El alemán puede dar explicaciones y establecer analogías que permitan a su amigo aproximarse a una vaga comprensión. Traducir no puede. Y la solución más directa será que el mbuti aprenda alemán y, como parte de lo mismo, el juego de lenguaje de vender y comprar. En tal aprendizaje, el alemán recurrirá a definiciones ostensivas, exhortará a su amigo a imitar acciones, lo corregirá, lo alentará, etc. — tal como describe Wittgenstein las escenas entre profesor y aprendiz que abundan en sus Investigaciones-.

La traducción — sea simple, sea compuesta - no sólo no es la única vía de acceso a otro lenguaje; tampoco es la vía principal. Y es que su funcionamiento presupone la existencia de un juego de lenguaje compartido, condición que en el encuentro con culturas lejanas precisamente tiende a no cumplirse. Emerge ahora, por lo demás, una caracterización de lo que he llamado ya varias veces un lenguaje lejano o una cultura lejana, sin elucidar la metaforicidad espacial de la expresión. Un lenguaje lejano al nuestro será aquel que en ocasiones no podamos traducir, y que nos obliga entonces a aprenderlo desde su interior, tal como aprendemos nuestra lengua materna; mientras más numerosas sean tales ocasiones, más alejado se hallará el lenguaje. Esto es cualquier cosa, menos un criterio que pueda presumir de exacto; la pertinencia de exactitud, empero, dista de ser aquí una cuestión incuestionable.

Aprender un lenguaje lejano desde su interior consiste, entonces, en aprender entretejimientos: usos de palabras incrustados en prácticas sociales más o menos complejas, como el comprar o vender en Europa, los sacrificios humanos en la antigua Ur o las riñas de gallos en la actual Bali. Como lo sugiere el ejemplo de Meløe, la comprensión intercultural pasa típicamente por la adquisición de nuevos juegos de lenguaje, nuevos contextos concretos de acción social. Es cierto que el entretejimiento de acciones y palabras no es menos característico de nuestro propio lenguaje; sin embargo, ocurre que en este caso tiende a pasar inadvertido, porque no lo experimentamos, no habitualmente, como obstáculo de la comprensión. Por ello mismo, en la comprensión intercultural podría verse un modelo de compresión en general: la historia del amigo mbuti hace patente una característica — el entretejimiento - que se halla también presente, aunque a menudo imperceptible, en toda comunicación por medio de un lenguaje. ${ }^{12}$

\footnotetext{
${ }^{12}$ No pretendo, con mucho, probar aquí tan ambiciosa afirmación, pero dejo sugerido que se la podría extraer de las investigaciones del segundo Wittgenstein.
} 
Ahora bien, la idea de los juegos de lenguaje sirve también para comprender mejor la comprensión de metáforas, porque también ésta acarrea la impronta de lo contextual, y en varios sentidos. Ya el hecho de si una oración es dicha en un sentido literal o metafórico depende de situaciones comunicativas particulares: de aquel que está hablando, de su interlocutor, de sus identidades sociales, de los temas de interés en ese momento, etc. Ser una metáfora no es una posible propiedad de una oración, sino de una emisión en un contexto preciso. ${ }^{13}$ Ahora bien, lo que vale para la identificación de enunciados metafóricos en cuanto tales, vale mucho más para su interpretación. Interpretar una metáfora implica, no menos que comprender una expresión de un lenguaje lejano, dominar un juego de lenguaje. En términos más concretos, comprender enfáticamente una metáfora implica poner en acción un contexto, crear incluso un nuevo contexto. ¿Qué puede significar esto? Lo explicaré a continuación, nuevamente a partir de un ejemplo. ${ }^{14}$

¿En qué consiste comprender una metáfora tan simple como "El árbol es tu amigo"? En algo nada simple, pero que se formula brevemente: en recontextualizar el tema de la ecología. Quien expuso esa oración por primera vez propuso el contexto de ciertas relaciones humanas para abordar la cuestión ecológica, un contexto que consideró adecuado o apropiado para ello. ${ }^{15}$ La predicación metafórica es la predicación de un contexto. El autor sitúa un tema (aquello de lo que habla una metáfora, su "asunto principal", como lo llamó Black) ${ }^{16}$ en un nuevo contexto, creando en cierto sentido un contexto que permite hablar novedosamente sobre el tema y comportarse frente a él de otra manera. Hablar de una creación no resulta exagerado, en

\footnotetext{
${ }^{13}$ Tan tajante afirmación podría ser objetada mediante ejemplos que yo mismo he usado. ¿Es que la oración "Un poema es un pavo real" puede no ser una metáfora? (Debo esta objeción, así como muchas otras valiosas sugerencias, a uno de los correctores anónimos de este trabajo.) La cuestión es, sin embargo, que tal reunión de palabras también podría constituir un simple abuso del lenguaje, mero sinsentido. Si las dijese un demente, no hablaríamos de una metáfora. Tampoco lo haríamos en el caso de un niño de tres o cuatro años que juega a asociar vocablos caprichosamente (con ese peculiar gusto por el absurdo que tienen los niños de tal edad). En tal sentido, independientemente de su emisión por parte de un hablante, no parece posible determinar una oración como metáfora.

${ }^{14}$ En lo que sigue retomo la tesis de fondo de Fermandois 2000. Sin embargo, la hipótesis comparativa que me guía en este artículo confiere a la siguiente descripción matices que no tuve en cuenta en aquél.

${ }^{15}$ En Fermandois 2000, pp. 96ss, explico el significado que tienen aquí las palabras "adecuado" o "apropiado".

${ }^{16}$ Cfr. Black 1999, p. 561.
} 
la medida en que la conjugación de tema y contexto es, en este caso, algo inédito. Por su parte, quienes comprenden la metáfora re-crean ese contexto, sirviéndose a veces de la recontextualización propuesta por el autor de modos que a éste sorprenderían (esto último se apreciará mejor en la sexta sección). Ahora bien, el contexto del cual hablamos en el caso de "El árbol es tu amigo" lo conforman no sólo las informaciones, sino también imágenes, sentimientos, modos de conducta y reacción, valoraciones éticas y no éticas, leyendas y tradiciones, etc., que típicamente asociamos al fenómeno de la amistad. ${ }^{17}$ La recontextualización del tema de los árboles abre incluso la posibilidad de formular preguntas hasta ahora insólitas, como, por ejemplo, si a un árbol le duele su maltrato. El enorme potencial crítico de esta metáfora obedece, entonces, al hecho de que no sólo se trata de generar o confirmar creencias sobre la cuestión ecológica, sino que de dar paso a una nueva actitud frente a ella, actitud que es mucho más que una suma de creencias y de la cual forman parte, en este caso, la indignación sobre ciertas actividades industriales y la adopción de medidas concretas en pos de su interrupción. Lo que se intuye muchas veces - y tan pocas se torna tema- como la riqueza de una metáfora, no es sino la imbricación de aspectos cognoscitivos, imaginativos, valorativos y emocionales en un solo enunciado; dicha imbricación se debe a que la metáfora no sólo opera en contextos específicos (la emisión proferida en circunstancias únicas e irrepetibles), sino que lo hace también con contextos tipificados (tipificados: como cuando se habla de "en el contexto de una entrevista laboral" o "en un contexto militar"). Lo expresado en este párrafo se resume fácilmente: la metáfora fuerte crea un nuevo juego de lenguaje.

De la dependencia contextual de la metáfora, en lo que toca a su identificación tanto como a su interpretación, se sigue la inexistencia de reglas. $\mathrm{O}$ mejor: dicha dependencia y dicha inexistencia se requieren como anversos de una medalla. Sobre todo en la interpretación de metáforas hay, sin duda, más creatividad que aplicación de criterios. Ahora bien, de acuerdo con la hipótesis de comparación que me lleva, en movimientos pendulares, de un fenómeno de comprensión al otro, debiera ahora afirmar algo análogo de la interpretación de otras culturas: que tampoco ésta se guía por reglas. Pues bien, es éste un pensamiento que hallamos en el corazón de la metodología

${ }^{17}$ Blumenberg apunta a esta misma complejidad con la siguiente enumeración: las metáforas absolutas "indican [...] las certezas, las conjeturas, las valoraciones fundamentales y sustentadoras que regalan actitudes, expectativas, acciones y omisiones, aspiraciones e ilusiones, intereses e indiferencias de una época" (Blumenberg 2003, p. 63). 
geertziana, como el siguiente puñado de citas debiera dejar en claro. En abierta reacción a la etnociencia o antropología cognitiva que concibe la cultura como una realidad mental o psicológica, y su estudio, como "la exposición de reglas sistemáticas, una especie de algoritmia etnográfica que, de ser seguida, haría posible obrar como [...] un nativo" (Geertz 2000a, p. 25), para nuestro autor el análisis de la cultura "no es una ciencia experimental en busca de leyes" (p. 20) y se parece mucho más a "la (tarea) del crítico literario" (p. 24), dado que "los escritos etnológicos son ellos mismos interpretaciones" (p. 28). Usando dos notables giros del gran escritor que Geertz también es: "una etnografía de la brujería escrita por un geómetra" no puede ser el modelo, como no lo puede ser tampoco "una etnografía de la brujería escrita por una bruja" (1994, p. 75).

\section{Descripción densa, red metafórica y profundidad}

En las observaciones que escribió Wittgenstein a propósito de La rama dorada de Frazer, se halla un pensamiento, repetido en diversas modulaciones, que permite entender cómo es siquiera posible que alguien llegue a comprender hábitos culturales que le son extraños. Evidente no lo es: ¿en virtud de qué puede un etnólogo occidental comprender prácticas de magia y brujería si éstas se hallan del todo ausentes en su forma de vida moderna? Pero esto último, nos dice Wittgenstein, no es tan cierto como parece. Nuestra cultura conoce prácticas análogas a las que nos impresionan en culturas recónditas, y es por razón de tal analogía que podemos llegar a comprenderlas. Cuando Wittgenstein escribe que "[t]oda una mitología está depositada en nuestro lenguaje" (1997, p. 25) no se está refiriendo al lenguaje en general, sino a un lenguaje específico de nuestra cultura moderna occidental; lo prueba el que inmediatamente antes haya llamado la atención sobre el hecho, tan poco atendido, de que nuestro léxico - castellano o alemán, para el caso da lo mismo- contemple voces como "alma" (Seele) y "espíritu" (Geist). Vale la pena recordar también el ejemplo de quien besa la foto del ser amado (cfr. 1997, p. 13) o la acción del hermano de Schubert tras la muerte de éste: cortó en pequeños pedazos varias partituras del músico y los repartió entre sus alumnos predilectos —un acto de piedad (Pietät), según Wittgenstein (cfr. 1997, p. 17)—. ${ }^{18}$ Para lograr comprender ritos y

\footnotetext{
${ }^{18}$ No sigo a Esquivel, quien traduce "Pietät" por "respeto", perdiendo así la connotación de una pagana religiosidad que me parece interesante. Otro ejemplo similar: que nuestro propio nombre tenga un carácter sagrado ( $c f r$. Wittgenstein 1997, p. 15).
} 
costumbres de otros seres humanos no podemos sino suponer que, en alguna medida, ellos son como nosotros. Y es que, como bien recuerda Wong, ese "nosotros" no es homogéneo, todo lo contrario (cfr. Wong 1989, pp. 142-144). Pues bien, es sacando provecho hermenéutico de las ambigüedades de la propia tradición, incluidos eventuales conflictos, como podemos acceder al lenguaje y las acciones de culturas lejanas. Decíamos antes que metaforizar (proponer y desentrañar metáforas) es esencialmente recontextualizar. Vemos ahora que comprender un rito ancestral o un acto de brujería también implica un movimiento recontextualizador, aunque no exactamente el mismo: es trasladar el lenguaje y las acciones que tanto nos impresionan a un contexto análogo, pero esta vez conocido; es ver los usos y acciones que poseen su sentido en un contexto aparentemente lejano, a la luz de un contexto cercano.

¿Es posible decir algo más sobre el proceso interpretativo que un etnólogo lleva adelante gracias a una analogía? La analogía es, por decirlo así, la condición de posibilidad de tal proceso; sin embargo, ¿cuál es su estructura? Aquí nos pueden ser de ayuda observaciones de Wittgenstein que se complementan de un modo sorprendente con otras de Geertz. Aludiendo a la práctica de matar a un sacerdote-rey en el apogeo de su vida y a la improcedencia de intentar explicarla, dice el primero: "Aquí sólo se puede describir y decir: así es la vida humana" (Wittgenstein 1997, p. 11). ${ }^{19}$ Poco después se pregunta qué significaría comentar dicha práctica con la expresión "la majestad de la muerte"; y responde: "Esto no es naturalmente una explicación, sino que es poner un símbolo en lugar de otro. $\mathrm{O}$ una ceremonia en lugar de otra" (p. 13). Ambas ideas - el carácter forzoso de la descripción y el reemplazo de símbolos por símbolos - reaparecen bajo una nueva terminología en la reflexión de Geertz e iluminan nuevos aspectos de la comprensión metafórica. Pero vamos por partes.

La mayor contribución teórica de Geertz fue llevar a la filosofía de las ciencias sociales, en los años setenta del siglo pasado, el término "descripción densa" (thick description) de Gilbert Ryle, confiriéndole así una significación metodológica impensada. La idea que dicho término recoge es, en esencia, la siguiente. Aludíamos recién a la fotografía del ser amado; pues bien, es posible dar muy distintas descripciones de ese objeto del mundo: puedo decir, por ejemplo, que se trata de un pedazo de papel fotográfico; o que es la fotografía

\footnotetext{
${ }^{19}$ Wittgenstein hace un uso muy restrictivo de la palabra "explicar", como prácticamente equivalente al de "explicación lógico-deductiva". Esta cuasiecuación es problemática, pero no me detendré en este punto.
} 
impresa de un ser humano; o la imagen de un niño jugando fútbol; o la foto de mi hijo que él mismo ha pedido que le saquen, para luego regalármela en el Día del Padre (sabiendo que esa institución no es de mi total agrado), y todo ello con el fin de que la ponga en mi oficina y pueda pensar a menudo en él, sobre todo, en sus últimos e importantes avances en el fútbol... Si tomamos ahora estas cuatro descripciones en el mismo orden en que las he presentado, Geertz diría que he ofrecido cuatro descripciones cada vez más densas del mismo objeto. Afirmar que se trata de un pedazo de papel fotográfico es dar una descripción superficial (thin description), casi vacía de interpretación y sentido. Este "casi" es importante, porque para Geertz no existen datos no interpretados, en contraste con la aspiración de positivistas lógicos y conductistas, que intentan presentar descripciones superficiales del todo. En el extremo opuesto de la lista tenemos, claro, la descripción más densa (y no sólo la más larga). También es correcto mantener que progresivamente fui ahondando mi comprensión del objeto, en el entendido de que existen diversos estratos de significado, cada vez más profundos, que mis descripciones fueron poniendo uno a uno al descubierto. Pues bien, lo que vale para la foto de mi hijo, vale también para cualquier manifestación simbólica: gestos, ritos, instituciones, leyendas, etc. La etnografía, según Geertz, no es sino descripción densa, pues se trata, como sugería Wittgenstein, de describir, describir y describir, para finalmente agregar, casi suspirando, que así es la vida humana. Esa prolongada descripción es siempre de carácter interpretativo; escribe Geertz: "los escritos antropológicos son ellos mismos interpretaciones, y por añadidura interpretaciones de segundo y tercer orden. (Por definición, sólo un 'nativo' hace interpretaciones de primer orden: se trata de su cultura)" (2000a, p. 28). Estas interpretaciones de segundo y tercer órdenes evocan indudablemente la sustitución de símbolos por símbolos, de ceremonias por ceremonias, de la cual habló antes Wittgenstein. El punto que importa es éste: en ninguno de esos dos casos se pretende abandonar, ni hacer como si se abandonara, el plano hermenéutico, el de ceremonias e interpretaciones; ninguno de los dos autores piensa que sea posible descender a un nivel supuestamente básico de hechos brutos, ni que sea pertinente buscar historias causales en vez de interpretativas.

¡Un último aspecto antes de volver a las metáforas!. . . Wittgenstein pone preocupado énfasis en que nuestra interpretación de la práctica lejana no nos puede hacer perder de vista la profundidad del fenómeno que se va a estudiar. Lo que nos impresiona es lo profundo. La palabra "profundidad" (Tiefe) se repite una y otra vez en la 
segunda parte de sus notas sobre Frazer. En el festival del fuego de Beltane, tal como se festejaba en la Europa del siglo XVIII, lo profundo es también lo terrible (das Finstere) de la ceremonia: una torta es partida en varios pedazos, uno de los cuales lleva una marca; se reparten los pedazos entre los presentes y la persona que recibe el pedazo marcado es tomada violentamente por los demás, que hacen como si la tiraran al fuego; de ahí en adelante todos hablan de aquella persona como si estuviera muerta. ${ }^{20} \mathrm{Si}$ entiendo bien estos pasajes, Wittgenstein intenta mostrar, por un lado, que ninguna explicación causal o histórica logrará dar cuenta de la profundidad de esta costumbre social. Bien podríamos no llegar nunca a conocer su verdadero origen, o las hipótesis actuales, según las cuales los individuos sorteados originalmente eran de hecho tirados al fuego, podrían revelarse más tarde como falsas; en ambos casos, sin embargo, seguiríamos sintiéndonos impresionados. Por otro lado, Wittgenstein quiere hacernos ver que el carácter profundo, eso terrible y misterioso (das Geheimnisvolle) de la práctica tal como se la realiza en el siglo XVIII, está en ella misma, en su "naturaleza interna" (1997, p. 33), en el "espíritu" del festival, el cual "quedaría descrito cuando, por ejemplo, se describiese al tipo de gente que toma parte en ellos [sic], el resto de sus formas de actuar, esto es, su carácter y el tipo de los demás juegos que practican" (1997, p. 33). Estas últimas palabras son un perfecto resumen - por adelantado- del paradigma hermenéutico de la descripción densa. Y es aquí adonde quería llegar: la profundidad que le importa a Wittgenstein corresponde a la descripción densa que practica Geertz. La única posibilidad de no desatender el carácter profundo de ciertos ritos, su carácter terrible a veces, es describiendo lo más densamente que se pueda. De acuerdo con Geertz, siempre quedará un resto de misterio, aun habiéndose hecho una descripción extremadamente densa; sin embargo, más no se puede hacer. También Wittgenstein llegó a escribir: "De la magia habría que conservar su profundidad."21

Las ideas anteriores son de provecho para entender mejor la comprensión metafórica. Se trata al menos de tres aspectos: 1) la importancia de la llamada red metafórica, 2) la idea de la profundidad de ciertas metáforas, y 3) un movimiento interpretativo que va, por decirlo así, de lo poco a lo mucho.

\footnotetext{
${ }^{20}$ Sobre el tema véase Cioffi 1981.

${ }^{21}$ Se trata, hay que decirlo, de una observación del manuscrito original de Wittgenstein 1997, que más tarde fue eliminada.
} 
1) Una metáfora fuerte puede generar no sólo una cantidad indeterminada de interpretaciones literales, sino que puede ser interpretada también mediante metáforas subsecuentes, "pequeñas metáforas" si se quiere, unidas y guiadas por una metáfora grande o central. Ésta presenta característicamente una tendencia a expandirse en una compleja red de metáforas menores - y porque hay complejidad y no sólo inferencia lineal, digo "red", más que "cadena"-. "Un poema es un estrechón de manos" nos sugiere que el poeta quiere saludar con aprecio a su lector, que durante el saludo lo mira a los ojos y quisiera abrazarlo, que le ofrece su sincera compañía futura, que se lava las manos antes de escribir sus versos... todo lo cual es, o puede ser, tan cierto como metafórico (y en parte hiperbólico). El fenómeno fue observado incipientemente por Black en su seminal artículo sobre la metáfora y, porque también otros autores lo han hecho, muy en particular Tirrell, no basta llamar la atención sobre él: debemos entenderlo mejor. ${ }^{22}$ En este punto, la comparación con la comprensión intercultural nos brinda una pista, en concreto, la insistencia de Wittgenstein y Geertz a mantenernos en el plano simbólico, el de las ceremonias. Esta pista nos conducirá, por de pronto, a la idea de que el fenómeno de la red metafórica está relacionado con la manera más productiva de interpretar metáforas.

Tomemos, por caso, la última de las interpretaciones que di a la metáfora de Celan: dije que el poeta se lava las manos antes de escribir sus versos. Si se la compara con el resto de mis parafraseos, se convendrá en que es éste el más metafórico de todos (una cuestión de grados, claro, como todo en nuestro tema). Pues bien, esa misma propiedad suya hace que, entre mis cuatro o cinco parafraseos, sea también aquel que más se presta para que la metáfora de Celan continúe ramificándose. Del lavado de manos podré sacar, a su vez, más metáforas, y algunas de ellas más metafóricas que otras. Podré decir, por ejemplo, que el poeta se prepara espiritualmente antes de comenzar a escribir, que ello implica tener cierta paz consigo mismo y que, seguramente, al escribir se volverá a ensuciar las manos. De nuevo, entre estas tres pequeñas interpretaciones de la ya pequeña metáfora del lavado de manos, la más metafórica es la última: ¿qué podrá querer decir que alguien se ensucia las manos al hacer poesía? Y de nuevo: de las tres interpretaciones, es esa última la que más nos invita a continuar hilvanando interpretaciones; ensuciarse las manos: trabajo arduo, confrontación con realidades odiosas, pero también (y nuevamente al final) llenarse las manos de polvo... aquel que somos

${ }^{22}$ Cfr. Black 1999 y Tirrell 1989.

Crítica, vol. 40, no. 118 (abril 2008) 
y en el que nos convertiremos. Lo que vamos obteniendo, entonces, es una estructura de ramificaciones subsecuentes. Pero no sólo eso; también son posibles conexiones entre los elementos pertenecientes a los diferentes racimos que vemos formándose. Así, parte de una comprensión enfática de la metáfora de Celan podría ser decir que frente al inapelable dictamen bíblico acerca de nuestro final, el poeta nos hace un cordial guiño de ojos lleno de complicidad, metáfora pequeña, esta última, extraída de la ya pequeña metáfora del poeta mirando los ojos de su lector como parte del estrechón de manos que es un poema. Lo que por de pronto pareciera un árbol ramificado es, en realidad, algo más complejo y menos estructurado. Ni siquiera es una red. Prefiero por ello, como Geertz, hablar de una historia: historia contada en varios niveles, historia vertida en remisiones directas e insinuaciones veladas, historia de nunca acabar.

Así, al tomar como modelo la interpretación de otras culturas se nos han revelado dos interesantes rasgos del carácter expansivo de las metáforas fuertes. En primer lugar, que la expansión será cada vez mayor, mientras más metáforas sean interpretadas mediante metáforas (una ceremonia con otra, como diría Wittgenstein). Nuestra interpretación de una metáfora fuerte podrá llegar incluso a territorios insospechados, si dejamos volar la imaginación de una metáfora en otra, en vez de aterrizar cada vez en interpretaciones literales. Importa, sin embargo, distinguir este planteamiento de una supuesta omnipresencia de la metáfora: la tesis de que todo el lenguaje es metafórico (Nietzsche, Gadamer, de Man, entre varios otros) o alguna tesis parecida (Derrida). Porque en el proceso de interpretación expansiva, tanto la metáfora principal, como cada una las pequeñas y aún más pequeñas metáforas, puede recibir, a su vez, algún comentario que diríamos literal. La interpretación densa de una metáfora contempla la participación de enunciados literales, por lo que no nos compromete con la idea — a mis ojos, problemática - de una ubicuidad de lo metafórico.

El segundo rasgo descubierto es que la interpretación de una metáfora no tiene tanto la estructura de un árbol ramificado, como la presentada por Tirrell en su estudio sobre la expansión metafórica. Tiene una estructura más compleja, lo cual nos ha llevado a decir que se parece a contar una historia, tal como, según Geertz, se debe contar una historia para interpretar densamente una costumbre social de otra cultura. Si queremos rescatar lo de una red, deberíamos hablar de varias redes e incluso de redes de diferentes materiales: nótese que en medio de mi interpretación de la metáfora de Celan, al referirme al polvo del que estamos hechos, cambié súbitamente de 
registro para servirme del viejo acervo bíblico, acervo que no estará disponible en una interpretación de la misma metáfora en contextos culturales diferentes. Lo que da finalmente cohesión interna a una interpretación metafórica no es que se relacionen entre sí elementos de un mismo registro, sino la plausibilidad de una historia que la fantasía de un intérprete urde a propósito de una sutil invitación.

2) ¿Qué es una metáfora profunda? Es otra cuestión del todo ausente en los estudios sobre la metáfora. De lo dicho se desprende, por de pronto, que no ha de pensarse en una propiedad inherente al enunciado metafórico. La profundidad de una metáfora no es sino la extensión, complejidad y proyección indefinida de su interpretación. Hans Blumenberg estudió las que llamó "metáforas absolutas", grandes imágenes filosóficas que buscan (sin nunca lograrlo del todo) dar respuesta a interrogantes que los seres humanos (sin poder evitarlo) nos planteamos una y otra vez. La luz de la verdad y la verdad desnuda; la vida concebida como travesía en alta mar; la remisión al reloj para dar una explicación del mundo; el estado cual organismo, el libro de la naturaleza — todas ésas son metáforas absolutas-. Ahora bien, la gran mayoría de nosotros vería en ellas metáforas que son profundas. Y dado que hablan de la vida, el mundo, el ser humano, es decir, de totalidades, no sería descabellado ver en ese rasgo distintivo aquello que les confiere profundidad. Sin embargo, esta última no es cuestión de temas; las metáforas absolutas simplemente generan la expectativa de poder ser interpretadas indefinidamente, es decir, no son necesariamente profundas - lo cual no es una crítica a Blumenberg, sino que, y atendiendo a sus libros, todo lo contrario-. Por otro lado, y consecuentemente, metáforas que sin tener la vida o el mundo por tema, o no al menos explícitamente, son - mejor: pueden llegar a ser- metáforas muy profundas. Aprendemos algo sobre comprender metáforas observando la práctica de Geertz: lo que hizo en su magistral estudio sobre las riñas de gallos en Bali fue mostrar precisamente que una práctica social que todos, tanto nativos como antropólogos (i.e., antropólogos que no suscriben la descripción densa), habrían considerado banal y superficial, es, muy por el contrario, una práctica que esconde una enorme profundidad de sentido: un deep play, como ya lo dice el título de aquel estudio. ${ }^{23}$ Con todo, sólo en la sección siguiente quedará más claro en qué sentido experimentamos a veces una metáfora como profunda.

\footnotetext{
${ }^{23}$ El largo ensayo de 1958 muestra que esta práctica no constituye simplemente una suerte de deporte decadente en el que jóvenes apuestan el poco dinero que tienen — todo lo cual es todavía una descripción bastante superficial—. Un sinfín de detalles
} 
3) El tercer aspecto guarda estrecha relación con el anterior. Señala Geertz que la descripción etnográfica consiste en estudios "microscópicos". "La meta es llegar a grandes conclusiones partiendo de hechos pequeños pero de contextura muy densa, prestar apoyo a enunciaciones generales sobre el papel de la cultura en la construcción de la vida colectiva relacionándolas exactamente con hechos específicos y complejos" (Geertz 2000a, p. 38). Sin una coma más ni una menos, esta afirmación se aplica impecablemente a la comprensión metafórica: "Hecho pequeño pero de contextura muy densa" es una estupenda definición de metáfora. Si damos crédito a la cita, el movimiento de la interpretación cultural va de menos a más, de lo intenso a lo extenso. Viene al caso recordar entonces la original analogía de Ricœur entre una metáfora y un texto en miniature. Efectivamente, la metáfora es un texto breve que leemos como si fuera extremadamente largo.

La dinámica ideal de la interpretación metafórica es entonces la de un despliegue progresivo (y no la de un "ahá"), como lo refleja el trabajo de generaciones de autores con las comprimidas metáforas que Blumenberg caracterizó como absolutas. Y a la inversa: la interpretación siempre abierta de metáforas fuertes tiene su parangón en la etnología. En la terminante sentencia de Geertz: "El análisis cultural es intrínsecamente incompleto" (Geertz 2000a, p. 39).

\section{Producción de sentido, circunstancia de cambio}

La condición expansiva de una metáfora y su profundidad bien entendida - localizada en la interpretación — son factores que ni siquiera podríamos concebir, sin asignar un papel eminentemente activo al intérprete. Ante un enunciado metafórico todo está por hacer. Por ello resulta iluminador que Cooper compare una metáfora (fuerte) con una fiesta ( $c f r .1986$, p. 242). Las fiestas no son ni buenas, ni regulares, ni malas en sí mismas: son los invitados quienes las hacen buenas, regulares o malas. Asimismo, cabe imaginarse a un profesor universitario recordando a sus estudiantes que los seminarios debieran ser fiestas (o metáforas). Y es que metáfora e indolencia mutuamente se oponen. Black puso alguna vez como ejemplo de metáfora malograda (failed) "Esta silla es un silogismo" (1993, p. 30), pero ello

elaborados por Geertz la hacen aparecer, en cambio, como una "forma de arte", cuyo papel es comparable al que podrían tener para nosotros King Lear o Crimen y castigo. La riña de gallos en Bali "recoge estos temas - muerte, masculinidad, furor, orgullo, pérdidas, ganancias, azar-y, al ordenarlos en una estructura general, los presenta de una manera tal que pone de relieve una particular visión de la naturaleza esencial de dichos temas" (Geertz 2000c, p. 364). 
no significa que sea imposible inventar una historia que hiciera de ese probable sinsentido una metáfora. Aunque Black no fue explícito al respecto, el problema está más bien en que sólo devendría metáfora en un contexto muy específico, irrepetible casi, lo cual la privaría de cualquier interés mayor. Por ese mínimo alcance de la eventual interpretación, más que por algo inherente a una inhabitual reunión de vocablos, Black efectivamente nombró una metáfora malograda: casi nadie vería sus experiencias reflejadas en la interpretación.

La metáfora genera expectativas, al igual que los dos puntos: en su admirable artículo sobre los signos de puntuación, Adorno cuenta que, según Karl Kraus, los dos puntos emulan una boca abierta, por lo que al usarlos debemos tener alimento que ofrecer ( $c f r$. Adorno 1974, p. 106). También, por cierto, el autor de una metáfora debe responder a tal exigencia. Sin embargo, ello en nada exime al intérprete de su propia labor, y en este contexto hay dos curiosos fenómenos que observar. Primero, que tomadas en sí mismas, es decir, mientras aún no arranca la interpretación, metáforas como "El mundo es un teatro" o "La vida es un carnaval" pueden generar algo parecido al tedio: las conocemos de sobra y por sí solas poco dicen. Y, segundo, que tales metáforas promueven a menudo, y paradójicamente, la inactividad: estando ya más o menos garantizada su comprensión básica, no nos tomamos el tiempo necesario para desplegarlas enfáticamente; las dejamos pasar y perdemos la oportunidad. ¿Qué oportunidad?

Nuestro paralelo general ilumina, por de pronto, una dimensión de la práctica antropológica que no resulta tan evidente o que podría resultar trivial. No es evidente en qué sentido no trivial cabe hablar de un papel activo de quien viaja a lugares lejanos para entregarse a la experiencia de culturas distintas. Pero si atendemos a lo que sobre tales viajes y estadías nos enseña la metarreflexión de Geertz, veremos que también en este caso la comprensión es productiva. Los escritos antropológicos son interpretaciones (de segundo y tercer órdenes), pero son también, y por lo mismo, ficciones, "ficciones en el sentido de que son algo 'hecho', algo 'formado', 'compuesto' - que es la significación de fictio-, no necesariamente falsas o inefectivas o meros experimentos mentales de "como si" (Geertz 2000a, p. 28). La práctica desconocida puede presentar el carácter de lo misterioso o enigmático, pero su interpretación no se parece al desciframiento de un mensaje encriptado. Se parece a la invención de una nueva lectura ( $c f r$. p. 24). La distinción que hicimos en el segundo apartado entre metáforas fuertes enigmáticas y metáforas fuertes que no lo son podría tomarse como si sólo las primeras ("Un poema es un pavo real") requiriesen un intérprete activo, no así, en cambio, metáforas 
como "El mundo es un teatro". Y esto, claro, resulta bastante contraintuitivo. Sin embargo, el sentido de esa distinción es otro y sólo tiene que ver con las características del encuentro: frente a metáforas no enigmáticas tenemos, sobre todo, la sensación de una promesa, de un potencial ilimitado de lecturas; ante las enigmáticas predomina, claro, la perplejidad, esa que no se mantiene al encenderse las luces de una fiesta sorpresa. Tanto en un caso como en el otro, empero, el intérprete es eminentemente productivo: compone historias.

Ahora bien, he dicho primero "activo" y luego, siguiendo a Geertz, "productivo"; y dado que se puede ser activo sin ser productivo, con lo segundo he dicho más que con lo primero. ¿Qué puede significar, en el caso de la metáfora, hablar de productividad o creatividad, en un sentido que no se diluya simplemente en la idea de acción? Esta productividad sensu stricto está relacionada con lo que se puede llamar la vida propia de una metáfora, la vida que adquiere una vez que su autor la pone en circulación (tal como los escritores hablan de la independencia que alcanzan sus obras al ser publicadas). Ocurre en ese momento que tanto el intérprete como el autor pueden dar con lecturas en las que el autor no pensó. Este se convierte, al desprenderse de su metáfora, en potencial intérprete, y obtiene entonces la posibilidad de introducir sentidos impensados a su antigua creación. En ambos casos, el del intérprete que halla nuevas lecturas y el del autor que se pone en su lugar, estamos, rigurosamente hablando, frente a una producción de sentido. Esto ya no es contribuir como invitado a que la fiesta salga buena; es armar una fiesta con la que el anfitrión ni siquiera soñó. La comprensión metafórica es siempre perfectible. Y Geertz no diría otra cosa de la comprensión intercultural.

En la visión estándar de la metáfora que debemos a Grice y Searle, ésta es considerada un uso lingüístico en que un hablante dice $p$, aunque quiere decir $q$; o bien — para el caso es igual— en el que diciendo $p$, quiere decir $q, r$ y $s-\mathrm{y}$ punto-. Este análisis, que concibe las metáforas como un tipo particular de actos de habla indirectos, funciona en ejemplares de metáforas convencionales, pero no en el caso de metáforas fuertes, las esencialmente abiertas. Ahora bien, hay otro aspecto que la visión estándar no contempla ni puede contemplar: que las metáforas conducen eventualmente tanto al intérprete como al autor, transformado en un intérprete más, a nuevos pensamientos sobre el tema en cuestión, y que por lo mismo nuestro mayor aprecio por ellas no pasa por el hecho de que puedan ser un eficiente medio de resumir pensamientos existentes $(q, r$ y $s)$. La novedad queda estructuralmente sin pensar en el modelo estándar. Respecto de ella, Rorty ha puesto las cosas en su lugar. Son tres las vías, nos dice, 
por las que llegamos a modificar nuestras creencias en general: por la percepción, la inferencia y la metáfora. Sin embargo, mientras que las dos primeras no alteran nuestro lenguaje, sino sólo el valor de verdad de ciertos enunciados, la metáfora, capaz de producir a la larga cambios semánticos, está asociada a la posibilidad de formar nuevos enunciados, modificando así el propio lenguaje ( $c f r$. Rorty 1993, p. 29). En muchas metáforas escuchamos un llamado, como apunta Rorty, a cambiar nuestro propio lenguaje y, en consecuencia, nuestra propia vida (cfr. 1993, p. 29). Es ésta la oportunidad que perdemos cuando las dejamos pasar. El cambio semántico, es decir, el enriquecimiento de nuestro lenguaje y nuestra vida está ligado a la aparición de nuevas metáforas que luego serán integradas en nuestros sistemas de creencias, pasando entonces a la literalidad.

Ahora bien, ésta es precisamente la oportunidad que caracteriza o debiera caracterizar toda comprensión intercultural: la de un posible cambio. El encuentro con el lenguaje de una cultura lejana puede enriquecernos si, por ejemplo, aprendemos ese lenguaje y, como parte de lo mismo, juegos de lenguaje que nos son desconocidos. Pero aquel encuentro puede también enriquecer nuestro lenguaje. Ello sucede en dos sentidos que importa distinguir. Puede ser que la necesidad de hablar sobre otra cultura nos obligue a crear palabras nuevas en nuestro lenguaje, modificándolo entonces en virtud de una ampliación. Así, para resolver el problema que planteaba el intraducible término alemán Erlebnis, con el específico matiz de inmediatez y pasividad que tienen algunas experiencias mentales subjetivas, Ortega y Gasset introdujo el neologismo "vivencia", ensanchando así nuestras posibilidades expresivas. Pero la modificación puede corresponder a un hecho diferente y, más propiamente hablando, modificador: el ajuste o acomodo de palabras viejas. Me interesa destacar esta última alternativa, pues habiendo sido muy severo con la traducción simple y compuesta, es el momento de rehabilitar otra variante de traducción. La mencioné al comienzo de la tercera sección, para olvidarla de inmediato: aquella traducción que, por transformar atrevidamente el sentido de expresiones de otro lenguaje, no permite que el traductor duerma en paz hasta ver publicadas sus famosas "notas". La relevancia de estas últimas nunca será suficientemente subrayada: confesándonos que ha traducido lo intraducible, el traductor nos hace ver en qué medida nuestras palabras significan lo que significan y nos lleva de paso a imaginar lo que podrían significar. Las notas a la traducción son la presentación comparada de diferentes posibilidades de vivir, como cuando se nos explica que areté no significa exactamente "virtud", porque los griegos... El original proyecto de Barbara Cassin de 
reunir en un diccionario los intraducibles de la filosofía europea - de reunir en un libro muchas notas a la traducción - reviste, por lo mismo, la mayor importancia cultural ( $c f r$. VEP 2004). Otra oportunidad de potencial transformación semántica y vital son las traducciones actualizadas de textos clásicos que contribuyen a configurar una forma de vida particular. En uno y otro caso, no se trata ya de palabras inventadas, sino que reinterpretadas. Sospecho que son los casos más interesantes: los del cambio propiamente tal y no los de una cuasicreación ex nihilo. Las palabras inventadas se refieren, en general, a intereses o descubrimientos prácticos o teóricos que, con todo lo importante que pueden llegar a ser, poseen en definitiva un carácter, por decirlo así, complementario (como la memoria de un computador o la navegación en internet); las palabras reinterpretadas a la luz de notas a traducciones atrevidas aluden, en cambio, a los aspectos más centrales o profundos de la vida (como la virtud, el amor, la razón o la democracia). Al referirme a los sentidos de la sorpresa metafórica dije que ciertas metáforas (así como ciertas costumbres ancestrales) "por alguna razón a indagar" nos continúan impresionando, a pesar de haberlas escuchado (o visto) miles de veces. Creo descubrir al menos parte de esa razón en lo siguiente: tanto en la comprensión intercultural como en la metafórica nos impresiona profundamente que, en virtud de ellas, podamos comenzar a ver ciertos temas de un modo completamente nuevo. Eso impresiona incluso al ateo cuando lee metáforas bíblicas. Eso impresiona al occidental que lee "Deep Play" de Geertz. Eso nos puede impresionar (si nos damos el tiempo) al leer "el árbol es tu amigo", "la vida es un teatro", "la pobreza es un delito", etc. Metáforas fuertes y prácticas culturales lejanas se parecen en que ambas representan posibles modos de vida. Y en tal sentido decimos a veces que son profundas.

\section{A modo de conclusión}

La razón de ser de toda cultura es hacer comprensible este extraño mundo, dotarlo de algún sentido mediante símbolos de los más diversos tipos. La función de un antropólogo es interpretar aquellos símbolos definidores de una cultura. Ahora bien, esa extraña mezcla de recintos, momentos, personajes y prácticas que conforman una cultura diferente, representa, en varios e importantes sentidos, una metáfora, y se la interpreta, en varios e importantes sentidos, como a ésta. Costumbres diferentes nos impresionan tanto como metáforas fuertes; la interpretación es, en ambos casos, inacabada; en vez de traducir, aprendemos y describimos; en un caso como en el otro nos 
valemos de los contextos, tanto para identificar como para comprender; describiendo densamente, sin abandonar el dominio simbólico y tejiendo historias, hacemos justicia a lo único que de verdad nos interesa: la profundidad de una práctica social desconocida o la promesa de profundidad de una metáfora; y cuando lo hacemos, aprovechamos oportunidades de cambio en nuestras palabras y vidas.

Según Geertz, una antropología hermenéutica persigue un doble objetivo: volver a sus lectores más conscientes sobre el hecho de que existen modos diferentes de pensar, pero hacerlos también más conscientes sobre cómo son en realidad sus modos propios. El suyo es un enfoque "que identifica, o casi, la aclaración sobre quiénes somos y la aclaración sobre entre quiénes estamos" (Geertz 2001, p. ix). Desconozco si Geertz suscribió también, aunque no me extrañaría, una idea que pareciera seguirse: sus descripciones densas podrían servir a una mejor interpretación, más rica y significativa, de las correspondientes prácticas por parte de sus propios actores, tal como nosotros podríamos ver enriquecida nuestra comprensión de prácticas propias, al conocer la interpretación que de ellas hacen miembros de otras culturas. Pues bien, esa posibilidad encuentra, me parece, un exacto paralelo en el hecho apuntado de que el autor de una metáfora puede transformarse en su intérprete. Los papeles se pueden intercambiar, la riqueza del fenómeno lo permite. Es posible obtener nuevas enseñanzas de las propias prácticas simbólicas (una metáfora, una costumbre, un rito) si se las enfrenta con otra mirada, la de un intérprete lejano.

Es curioso: no habiendo reflexionado explícitamente sobre la interpretación de metáforas, Wittgenstein y Geertz ayudan a comprenderla con mayor profundidad. ${ }^{24}$

\section{BIBLIOGRAFÍA}

Adorno, Theodor, 1974, "Satzzeichen", Noten zur Literatur, Suhrkamp, Fráncfort del Meno, pp. 106-113.

Black, Max, 1999, "La metáfora", en Valdés 1999, pp. 549-567. , 1993, "More about Metaphor", en A. Ortony (comp.), Metaphor and Thought, 2a. ed., Cambridge University Press, Cambridge, pp. 1941.

Blumenberg, Hans, 2003, Paradigmas para una metaforología, Trotta, Madrid.

${ }^{24}$ Escribí este trabajo con el apoyo del Programa Fondecyt, en el marco del proyecto de investigación "La comprensión de metáforas y su importancia para la comprensión lingüística en general" (Proyecto no. 1050872). 
Cioffi, Frank, 1981, "Wittgenstein and the Fire-festivals", en I. Block (comp.), Perspectives on the Philosophy of Wittgenstein, Blackwell, Oxford.

Cohen, Ted, 1979, "Metaphor and the Cultivation of Intimacy", en S. Sacks (comp.), On Metaphor, The University of Chicago Press, Chicago, pp. 110 .

Cooper, David, 1986, Metaphor, Blackwell, Oxford.

Davidson, Donald, 1999, "Lo que significan las metáforas", en Valdés 1999, pp. 568-587.

—_, 1995, "Interpretación radical", en De la verdad y la interpretación, trad. Guido Filippi, Gedisa, Barcelona, pp. 137-150.

Fermandois, Eduardo, 2003, "Wittgenstein: entre pragmatismo y relativismo", en S. Cabanchik et al. (comps.), El giro pragmático en la filosofía contemporánea, Gedisa, Barcelona, pp. 75-92.

—_ 2000, "Verdad y metáfora: una aproximación pragmática", Crítica, vol. 32, no. 95, pp. 71-102.

Frankfurt, Harry, 2006, On Bullshit. Sobre la manipulación de la verdad, trad. Miguel Candel, Paidós, Barcelona.

Geertz, Clifford, 2001, Available Light: Anthropological Reflections on Philosophical Topics, Princeton University Press, Princeton.

—, $2000 a$, "Descripción densa: hacia una teoría interpretativa de la cultura", en Geertz 2000b, pp. 19-40.

— $2000 \mathrm{~b}$, La interpretación de las culturas, trad. Alberto L. Bixio, Gedisa, Barcelona, pp. 339-372.

- 2000c, "Juego profundo: notas sobre la riña de gallos en Bali", en Geertz 2000b, pp. 339-372.

—, 1994 , “'Desde el punto de vista del nativo': sobre la naturaleza del conocimiento antropológico", Conocimiento local, trad. Alberto López Bargados, Paidós, Barcelona, pp. 73-90.

Hesse, Mary, 1993, "Models, Metaphors and Truth", en F.R. Ankersmit y J.J.A. Mooij (comps.), Knowledge and Language. Volume III: Metaphor and Knowledge, Kluwer, Dordrecht, pp. 49-65.

Hester, Marcus, 1966, "Metaphor and Aspect Seeing", The Journal of Aesthetics and Art Criticism, vol. 25, pp. 205-212.

Meløe, Jakob, 1986, "Über Sprachspiele und Übersetzungen”, en D. Böhler et al. (comps.), Die pragmatische Wende, Suhrkamp, Fráncfort del Meno, pp. 113-130.

Quine, Willard van Orman, 1968, Palabra y objeto, trad. Manuel Sacristán, Labor, Barcelona.

Ricœur, Paul, 1974, "Metaphor and the Main Problem of Hermeneutics", New Literary History, vol. 6, pp. 95-110.

Rivano, Juan, 1986, Perspectivas sobre la metáfora, Editorial Universitaria, Santiago.

Rorty, Richard, 1996, "Ruidos poco conocidos: Hesse y Davidson sobre la metáfora", Objetividad, relativismo y verdad, trad. Jorge Vigil Rubio, Paidós, Barcelona, pp. 223-236. 
Rorty, Richard, 1993, "Filosofía como ciencia, como metáfora y como política", Ensayos sobre Heidegger y otros pensadores contemporáneos, trad. Jorge Vigil Rubio, Paidós, Barcelona, pp. 25-47.

Tirrell, Lynne, 1989, "Extending: The Structure of Metaphor", Noûs, vol. 23, pp. 17-34.

Valdés, Luis Manuel (comp.), 1999, La búsqueda del significado, 3a. ed., Tecnos, Madrid.

Vocabulaire Européen des Philosophies. Dictionnaire des Intraduisibles (VEP), 2004, ed. Barbara Cassin, Seuil/Le Robert, París.

Williams, Bernard, 2006, Verdad y veracidad, trad. Alberto Enrique Álvarez y Rocío Orsi, Tusquets, Barcelona.

Wittgenstein, Ludwig, 1997, Comentarios sobre La rama dorada, 2a. ed., trad. Javier Esquivel, Instituto de Investigaciones Filosóficas-UNAM, México.

—_ 1988, Investigaciones filosóficas, trad. Adolfo García Suárez y C. Ulises Moulines, Crítica/Instituto de Investigaciones Filosóficas-UNAM, Barcelona/México.

Wong, David, 1989, "Three Kinds of Incommensurability", en M. Krausz (comp.), Relativism, Interpretation and Confrontation, University of Notre Dame Press, Notre Dame, pp. 140-158.

Recibido el 1 de octubre de 2007; aceptado el 19 de febrero de 2008. 